\title{
Engine Emissions at Various Cetane Numbers with Exhaust Gas Recirculation
}

\author{
B Lakshmana Swamy ${ }^{1 *}$, Dr. K Vijaya Kumar Reddy ${ }^{2}$, \\ Dr. B Sudheer Prem Kumar ${ }^{3}$ \\ 1. Associate Professor, Mechanical Engineering Dept., Aurora's Engineering College, Bhongir, Hyderabad, \\ Andhra Pradesh, India. \\ 2. Professor, Mechanical Engineering Department, Jawaharlal Nehru Technological University-Hyderabad, \\ Andhra Pradesh, India. \\ 3. Professor \&Head, Mechanical Engineering Department, Jawaharlal Nehru Technological University- \\ Hyderabad, Andhra Pradesh, India.
}

\begin{abstract}
Typical engine fuels are blends of various fuels species, i.e., multi component. Thus, the original single component fuel vaporization model was replaced by a multi component fuel vaporization model . The model has been extended to model diesel sprays under typical diesel conditions, including the effect of fuel cetane number variation. Necessary modifications were carried out at the various cooling rates. Found the performance of the diesel engine under various cooling rates at various cetane numbers, also various quantities of exhaust gas was re circulated and found performance of the engine.
\end{abstract}

\section{Introduction:}

Air pollution is referred addition harmful foreign particles or additives to the atmospheric air. The most of air pollution to the atmospheric is contributed by automobile engine emissions. The main emissions from the auto motive engine are oxides of nitrogen, oxides of sulphur, carbon dioxide, carbon monoxide, suspended or particulate matter, unused oxygen, and un burnt hydro carbons. Each of these pollutants has their own evil effect on the environment. Hence many efforts are made and many researches have been conducting to reduce these emissions without effecting the performance of the engine.

The cetane number is evaluated directly as a function of fuel composition. By using a blend of cetane (hexadecane) which has a cetane number of 100 , and iso cetane(a-methyl-naphthalene) which has a cetane number of 0 , it is possible to achieve blends with a wide range of cetane numbers. Moreover, the cetane numbers used in the ignition model are the local values of cetane number within the engine since the two components could be vaporizing at different rates due to their volatility differentials.

Combustion - In diesel engines, a significant portion of combustion is thought to be mixing-controlled. Hence, inter actions between turbulence and chemical reactions have to be considered. A laminar-and-turbulent characteristic-time combustion model was used for the present study. The local time rate of change of the partial density of species $\mathrm{m}$, due to conversion from one chemical species to another, is given by

$$
\frac{d \mathrm{Y}_{m}}{d \mathrm{t}}=-\frac{\mathrm{Y}_{m}-\mathrm{Y}_{m}^{*}}{\tau_{\mathrm{c}}}
$$

where $\mathrm{Ym}$ is the mass fraction of species $\mathrm{m}, \mathrm{Y}_{\mathrm{m}}{ }_{\mathrm{m}}$ is the local and instantaneous thermodynamic equilibrium value of the mass fraction, and $\tau$ is the characteristic time for the achievement of equilibrium. To predict thermodynamic equilibrium temperatures accurately, it is sufficient to consider seven species: fuel, 02, N2, $\mathrm{CO} 2, \mathrm{CO}, \mathrm{H} 2$, and $\mathrm{H} 20$, and to assume that the characteristic time is the same for all seven. As was previously assumed for the ignition model, the two fuel species are combined into an "effective" fuel for the purposes of the present implementation of the combustion model.

\section{A. Mechanism of formation of Carbon Monoxide (CO)}

\section{Mechannism Of Formation Of Pollutant}

Carbon monoxide is a colour less poisonous gas. Small amounts of CO concentrations, when breathed in, slow down physical and mental activity and produces headaches, while large concentration will kill. CO is generally formed when the mixture is rich in fuel. The amount of $\mathrm{CO}$ formation increases as the mixture becomes more and more rich in fuel. A small amount of $\mathrm{CO}$ will come out of the exhaust even when the mixture is slightly lean in fuel because air- fuel mixture is not homogenous and equilibrium is not established when the 
products pass to the exhaust. At the high temperature developed during the combustion, the products formed are unstable and following reactions take place before the equilibrium is established .

$$
2 \mathrm{C}+\mathrm{O} 2=2 \mathrm{CO}
$$

As the products cool down to exhaust temperature, major part of $\mathrm{CO}$ reacts with oxygen to form $\mathrm{CO} 2$. However, a relatively small amount of $\mathrm{CO}$ will remain in exhaust.

\section{B. Mechanism of formation of Hydrocarbons (HC)}

Hydrocarbons, derived from unburnt fuel emitted by exhausts, engine crankcase fumes and vapour escaping from the carburetor are also harmful to health. Hydrocarbons appears in exhaust gas due to local rich mixture pockets at much lower temperature than the combustion chamber and due to flame quenching near the metallic walls. A significant of this unburnt $\mathrm{HC}$ may burn during expansion and exhaust strokes if oxygen concentration and exhaust temperature is suitable for complete oxidation [2]. C. Mechanism of formation of nitric oxide (NO) of nitrogen is produced in very small quantities can cause pollution. While prolonged exposure of oxides of nitrogen is dangerous to health. Oxides of nitrogen which occurs only in the engine exhaust are a combination of nitric oxide (NO) and nitrogen dioxide (NO2). Nitrogen and oxygen react at relatively high temperature. NO is formed inside the combustion chamber in post-flame combustion process in the high temperature region. The high peak combustion temperature and availability of oxygen are the main reasons for the formation of NOx. In the present of oxygen inside the combustion chamber at high combustion temperatures the following chemical reactions will takes place behind the flame [2].

$$
\begin{gathered}
\mathrm{N} 2+\mathrm{O} 2=2 \mathrm{NO} \\
\mathrm{N} 2+2 \mathrm{H} 2 \mathrm{O}=2 \mathrm{NO}+\mathrm{H} 2
\end{gathered}
$$

Calculation of chemical equilibrium shows that a significant amount of $\mathrm{NO}$ will be formed at the end of combustion. The majority of NO formed will however decompose at the low temperatures of exhaust. But, due to very low reaction rate at the exhaust temperature, a part of NO formed remains in exhaust. The NO formation will be less in rich mixtures than in lean mixtures. The concentration of oxides of nitrogen in the exhaust is closely related peak combustion temperature inside the combustion chamber.

\section{Control Of Oxides Of Nitrogen(Nox)}

Many theoretical and experimental investigation shows that the concentration of NOx in the exhaust gas is closely related to the peak cycle temperature and available amount of oxygen in the combustion chamber. Any process to reduce cylinder peak temperature and concentration of oxygen will reduce the oxides of nitrogen. This suggests a number of methods for reducing the level of nitrogen oxides. Among these the dilution of fuel-air mixture entering the engine cylinder with an inert or non-combustible substance is one which absorbs a portion energy released during the combustion, thereby affecting an overall reduction in the combustion temperature and consequently in the NOx emission level. The following are the three methods for reducing peak cycle temperature and thereby reducing NOx emission .

1. Water injection.

2. Catalyst

3. Exhaust gas recirculation ( EGR)

\section{A. Water injection}

Nitrogen oxides NOx reduction is a function of water injection rate. NOx emission reduces with increase in water injection rate per $\mathrm{kg}$ of fuel. The specific fuel consumption decreases a few percent at medium water injection rate. The water injection system is used as a device for controlling the NOx emission from the engine exhaust.

\section{B. Catalyst}

A copper catalyst has been used to reduce the NOx emission from engine in the presence of CO. Catalytic converter package is use to control the emission levels of various pollutants by changing the chemical characteristics of the exhaust gases. Catalyst materials such as platinum and palladium are applied to a ceramic support which has been treated with an aluminium oxide wash coat. This results in as extremely porous structure providing a large surface area to stimulate the combination of oxygen with $\mathrm{HC}$ and $\mathrm{CO}$. This oxidation process converts most of these compounds to water vapour and carbon dioxide.

\section{Exhaust gas recirculation (EGR)}

EGR is commonly used to reduce NOx in S.I. engines as well as C.I. engines. The principle of EGR is to recirculate about $10 \%$ to $30 \%$ of the exhaust gases back into the inlet manifold where it mixes with the fresh air and this will reduces the quantity of $\mathrm{O} 2$ available for combustion [1,12]. This reduces the $\mathrm{O} 2$ concentration and dilutes the intake charge, and reduces the peak combustion temperature inside the combustion chamber 
which will simultaneously reduce the NOx formation. About $15 \%$ recycle of exhaust gas will reduce NOx emission by about $80 \%$. It should be noted that most of the NOx emission occurs during lean mixture limits when exhaust gas recirculation is least effective. The exhaust gas which is sent into the combustion chamber has to be cooled so that the volumetric efficiency of the engine can be increased. EGR ratio is defined as the ratio of mass of recycled gases to the mass of engine intake. Also \%EGR is From above three methods, EGR is the most efficient and widely used system to control the formation of oxides of nitrogen inside the combustion chamber of I.C. engine. The exhaust gas for recirculation is taken through an orifice and passed through control valves for regulation of the quantity of recirculation . Normally exhaust gas recirculation is shut off during idle to prevent rough engine operation.

EGR is a very useful technique for reducing the NOx emission. EGR displaces oxygen in the intake air and dilute the intake charge by exhaust gas recirculated to the combustion chamber. Recirculated exhaust gas lower the oxygen concentration in combustion chamber and increase the specific heat of the intake air mixture, which results in lower flame temperatures. It was observed that $15 \%$ EGR rate is found to be effective to reduce NOx emission substantially without deteriorating engine performance in terms of thermal efficiency, bsfc and emissions. Thus, it higher rate of EGR can be applied at lower loads and lower rate of EGR can be applied at higher load. EGR can be applied to diesel engine fueled with diesel oil, biodiesel, LPG, hydrogen, etc without sacrificing its efficiency and fuel economy and NOx reduction can thus be achieved.

EGR is a useful technique for reducing NOx formation in the combustion chamber. Exhaust consists of $\mathrm{CO} 2$; 2 and water vapours mainly. When a part of this exhaust gas is re-circulated to the cylinder, it acts as diluent to the combusting mixture. This also reduces the $\mathrm{O} 2$ concentration in the combustion chamber. The specific heat of the EGR is much higher than fresh air, hence EGR increases the heat capacity (specific heat) of the intake charge, thus decreasing the temperature rise for the same heat release in the combustion chamber.

\section{Experimental procedure:}

$\% E G R=($ volume of EGR/ total intake charge into the cylinder $) * 100$

Series of several experimental cycles were conducted with varying conditions of EGR substitutions and iterations were done with varying blends of different cetane numbers and the results were compared.

The exhaust gas analyzer used is MN-05 multi gas analyzer(4 gas version) is based on infrared spectroscopy technology with signal inputs from an electrochemical cell. Non-dispersive infrared measurement techniques uses for $\mathrm{CO}, \mathrm{CO} 2$, and $\mathrm{HC}$ gases. Each individual gas absorbs infrared radiation absorbed can be used to calculate the concentration of sample gas. Analyzer uses an electrochemical cell to measure oxygen concentration. It consist of two electrodes separated by an electrically conducted liquid or cell. The cell is mounted behind a polytetra fluorethene membrane through which oxygen can diffuse. The Device therefore measures oxygen partial pressure. If a polarizing voltage is applied between the electrodes the resultant current is proportional to the oxygen partial pressure.

The engine used in the present study is a Kirloskar AV-1, single cylinder direct injection, Water cooled diesel engine with the specifications given in Table 1. Diesel injected with a nozzle hole of size $0.15 \mathrm{~mm}$.the engine is coupled to a dc dynamometer. Engine exhaust emission is measured. Load was varied from 1 kilo watt to 3 kilo watts. The amount of exhaust gas sent to the inlet of the engine is varied. At each cycle, the engine was operated at varying load and the emissions were noted. The experiment is carried out by keeping the compression ratio constant i.e., 16.09:1.

Table of engine specifications:

\begin{tabular}{|c|c|}
\hline Type & $\begin{array}{c}\text { Four- stroke, single cylinder, Compression } \\
\text { ignition engine, with variable compression } \\
\text { ratio. }\end{array}$ \\
\hline Make & Kirloskar AV-1 \\
\hline Rated power & $3.7 \mathrm{KW}, 1500 \mathrm{RPM}$ \\
\hline Bore and stroke & $80 \mathrm{~mm} \times 110 \mathrm{~mm}$ \\
\hline Compression ratio & $16.09: 1$, variable from 13.51 to 19.69 \\
\hline Cylinder capacity & $553 \mathrm{cc}$ \\
\hline Dynamometer & Electrical-AC Alternator \\
\hline Orifice diameter & $20 \mathrm{~mm}$ \\
\hline Fuel & Diesel and Biodiesel \\
\hline Calorimeter & Exhaust gar calorimeter \\
\hline Cooling & Water cooled engine \\
\hline Starting & Hand cranking and auto start also provided \\
\hline
\end{tabular}

Table: 1 specifications of engine 


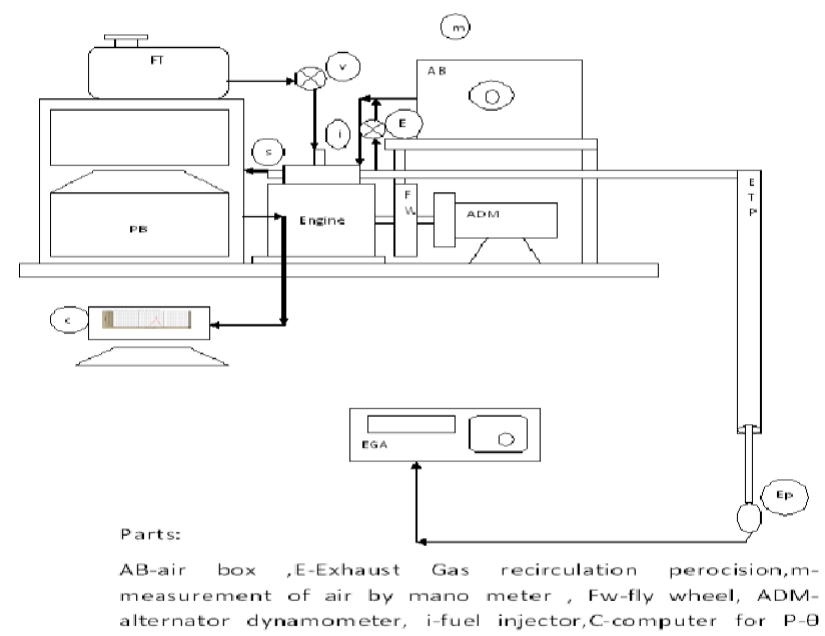

Fig: 1 block diagram of experimental set up

Parts:

AB-air box ,E-exhaust gas recirculation provision ,m- measurement of air by mano meter, Fw-fly wheel, ADM-alternator dynamometer, i-fuel injector,C-computer for P- $\theta$ inter face, $\mathrm{v}$-valve for fuel control, EGA-exhaust gas analyser, s-piezo electric sensor for $\mathrm{p}-\theta$ inter facing,PB- panel board, EP-exhaust gas probe, FT-fuel tank

\section{Nomenclature:}

\begin{tabular}{|c|c|}
\hline $\mathrm{NO}_{\mathrm{X}}$ & Oxides of nitrogen \\
\hline $\mathrm{CO}$ & Carbon monoxide \\
\hline $\mathrm{CO}_{2}$ & Carbon dioxide \\
\hline $\mathrm{HC}$ & Unburnt hydro carbons \\
\hline $\mathrm{PPM}$ & Parts per million \\
\hline $\mathrm{CR}$ & Peoling rate in LPM \\
\hline \%vol & $\begin{array}{c}95 \% \text { diesel }+5 \% \text { oferosene } \\
(\mathrm{CN}=48)\end{array}$ \\
\hline Blend1 & $\begin{array}{c}\text { CN }=45) \\
\text { Cetane number }\end{array}$ \\
\hline Blend2 & $\begin{array}{c}90 \% \text { diesel }+10 \% \text { erosene } \\
\text { CN }\end{array}$ \\
\hline
\end{tabular}

Table2: Nomenclature

\section{Results:}

Significant results were obtained after conducting of several experimental cycles with varying EGR substitutions and blends at different loads.

\section{NOx emissions:}

Graph 1 show that induction of EGR in the engine reduces the $\mathrm{NO}_{\mathrm{x}}$ because EGR reduces the intake of excess oxygen into the engine and there by reducing the formation of oxides of nitrogen. Emissions at various blends is shown in the graph1.

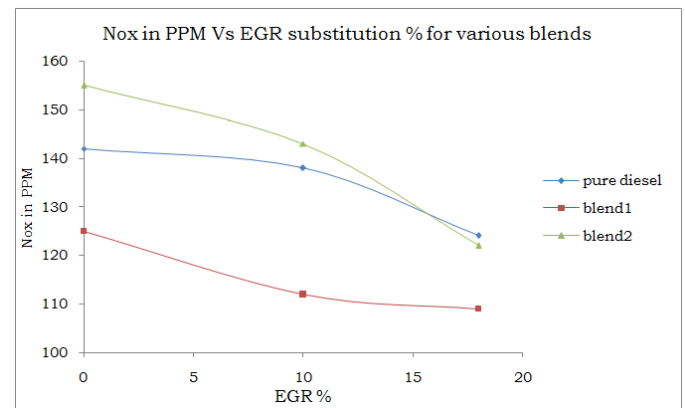

Graph1: Nox in PPM Vs EGR substitution \% for various blends 


\section{CO emissions:}

Carbon monoxide formation is due to carbon particles which are not totally oxidized. Induction EGR has decreased oxygen content in the combustion chamber there by reducing the oxidation of carbon flakes and increases the formation of $\mathrm{CO}$. But as seen from graph2 he increase in $\mathrm{CO}$ emissions due to EGR induction was not so substantial and was not more than $4 \%$ of that of condition when operated with blend $1 \& 2$.

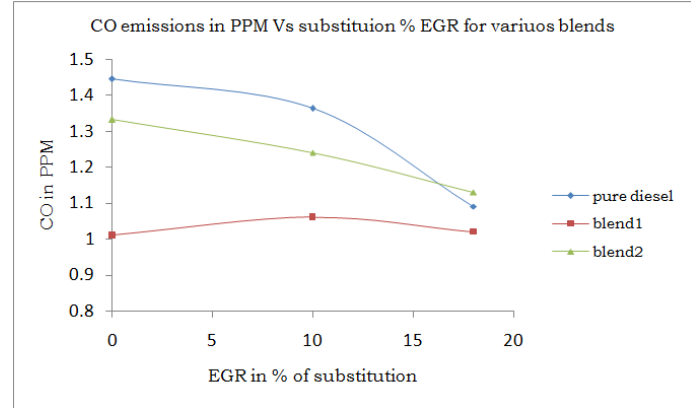

Unreacted oxygen:

Graph2: CO emissions in PPM Vs substitution \% EGR for various blends

Induction of EGR clearly reduces the intake of oxygen and hence leading to reduction in out come of unused oxygen. Graph 3 shows $26 \%$ reduction in un reacted oxygen when compared to that of operation without EGR at pure diesel and also for blend $1 \& 2$.

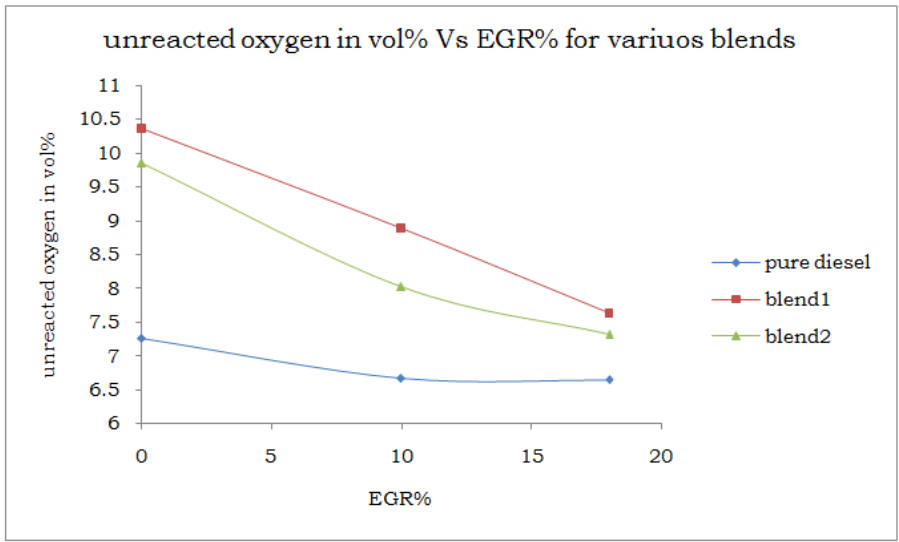

Graph3: un reacted oxygen in vol\% Vs EGR\% for various blends

\section{$\mathrm{CO}_{2}$ emissions:}

Graph 4 shows that increase in the EGR substitution of the engine any how increased the $\mathrm{CO}_{2}$ emissions by $19 \%$ to that of operation of engine without EGR.

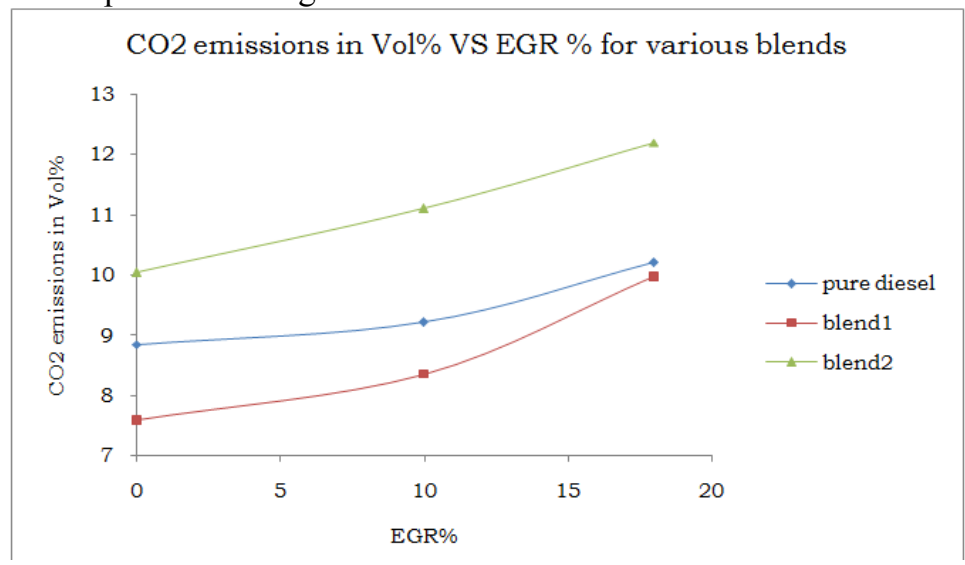

\section{HC emissions:}

Graph4: CO2 emissions in Vol\% VS EGR \% for various blends

From graph 5 it is inferred that increased EGR substitution has decreased the HC formation due to reduced by $7 \%$ nearly at all blends and diesel. 


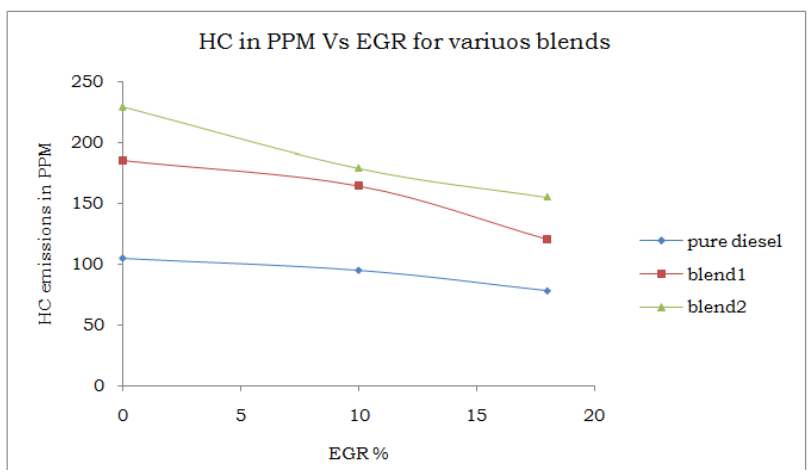

Graphs5: HC in PPM Vs EGR for various blends

\section{Results:}

Significant conclusions were drawn from after conducting of several experimental cycles with varying EGr substitutions and Blends at peak loads and observing the results.

- Induction of EGR in the engine reduces the $\mathrm{NO}_{\mathrm{x}}$ because EGR reduces the intake of excess oxygen into the engine and there by reducing the formation of oxides of nitrogen.

- Carbon monoxide formation is due to carbon particles which are not totally oxidized. Induction EGR has decreased oxygen content in the combustion chamber there by reducing the oxidation of carbon flakes and increases the formation of $\mathrm{CO}$. But as seen from graph2 he increase in $\mathrm{CO}$ emissions due to EGR induction was not so substantial and was not more than $4 \%$ of that of condition when operated with blend $1 \& 2$.

- Induction of EGR clearly reduces the intake of oxygen and hence leading to reduction in out come of unused oxygen. Graph 3 shows $26 \%$ reduction in un reacted oxygen when compared to that of operation without EGR at pure diesel and also for blend $1 \& 2$.

- Increase in the EGR substitution of the engine any how increased the $\mathrm{CO}_{2}$ emissions by $19 \%$ to that of operation of engine without EGR.

- The increased EGR substitution has decreased the HC formation due to reduced by $7 \%$ nearly at all blends and diesel.

\section{References:}

[1]. A Text book on "Internal Combustion Engine" by Domkunwar Text book on "Internal Combustion Engine" by R.K.Rajput.

[2]. Harilal S. Sorathia*, Dr. Pravin P. Rahhod and Arvind S. Sorathiya "EFFECT OF EXHAUST GAS RECIRCULATION (EGR) ON NOx EMISSION FROM C.I. ENGINE” - A REVIEW STUDY, International Journal of Advanced Engineering Research and Studies E-ISSN2249-8974

[3]. Kyung-Wook Choi, Ki-Bum Kim and Ki-Hyung Lee* "Investigation of emission characteristics affected by new cooling system in a diesel engine"in Journal of Mechanical Science and Technology 23 (2009) 1866 1870.

[4]. Avinash Kumar Agrawal_1, Shrawan Kumar Singh2, Shailendra Sinha1 And Mritunjay Kumar,” Effect of EGR on the exhaust gas temperature and exhaust opacity in compression ignition engines" $S^{-}{ }^{-}$dhan ${ }^{-} a$ Vol. 29, Part 3, June 2004, pp. 275-284. C Printed in India.

[5]. Gonzalez, M.A., Lian, Z.W. and Reitz, R.D."Modeling Diesel Engine Spray Vaporization and Combustion,” SAE Technical Paper $920579,1992$.

[6]. Poublon, M., Patterson, D., and Boerma, M.,"Instantaneous crank speed variations as related to engine starting," SAE Paper 850482,1985 .

[7]. Henein, N. A., and Zadeh, A., "Diesel cold starting Actual cycle analysis under borderline conditions,"

[8]. SAE Paper 900441,1990.

[9]. Halstead, M., Kirsh, L. and Quinn, C. "The Auto ignition of Hydrocarbon Fuels at High Temperatures and Pressures - Fitting of a Mathematical Model," Combust. Flame, 30, 45-60,1977.

[10]. Kong, S.C. and Reitz, R.D. "Multidimensional Modeling of Diesel Ignition and Combustion Using a Multistep Kinetics Model," ASME Transactions, Journal of Engineering for Gas Turbines and Power, Vol.115, pp. 781-789,1993.

[11]. Kong, S.C., Han, Z., and Reitz, R.D., "The Development and Application of a Diesel Ignition and Combustion Model for Multidimensional Engine Simulations," SAE Paper 950278,199s.

[12]. Ramos, J.I., Internal Combustion EnPine Modeling Hemisphere Publishing, NY, 1989.

[13]. Heywood, J.B., Internal Combustion Engine Fundamental McGraw-Hill, wml988.

[14]. Kong, S.C. and Reitz, R.D., "Spray Combustion Processes in Internal Combustion Engines," in Recent Advances in Sorav Combustion, AIAA Series, Editor K.K. Kuo, to appear 1995.

[15]. Giangregorio, R.P., Zhu, Y. and Reitz, R.D.,"Application of Schlieren Optical Techniques for theMeasurement of Gas Temperature and Turbulent Diffusivity in a Diesel Engine," SAE Technical Paper930869,1993.

[16]. Neluner, D.A. and Reitz, R.D., "Measurement of the Effect of Injection Rate and Split Injections on Diesel Engine Soot and NOx Emissions," SAE Paper 940668,1994.

[17]. Nehmer, D.A., "Measurement of the Effect of Injection Rate and Split Injections on Diesel EngineSoot and NOx Emissions," MS Thesis, Univ. o Wisconsin, 1993.

[18]. A.S., Kuleshov ( 2005) "Model for Predicting Air-Fuel Mixing, Combustion and Emissions in DI Diesel Engines over whole Operating Rang” S.A.E. paper 01-2119. 